5

\title{
Model validation and stochastic stability of a hydro-turbine governing system under hydraulic excitations
}

\author{
Beibei Xu' ${ }^{\mathrm{a}}$, Diyi Chen* ${ }^{\mathrm{a}}$, Silvia Tolo ${ }^{\mathrm{b}}$, Edoardo Patelli ${ }^{\mathrm{b}}$, Yanlong Jiang ${ }^{\mathrm{c}}$ \\ ${ }^{a}$ Institute of Water Resources and Hydropower Research, Northwest A\&F University, Shaanxi \\ Yangling 712100, P. R. China \\ ${ }^{b}$ Institute for Risk and Uncertainty, Chadwick Building, University of Liverpool, Peach Street,
} Liverpool L69 7ZF, United Kingdom

${ }^{c}$ The Yellow River Qinghai Hydropower Development Co., Ltd., Qinghai Xining 810000, P. R. China

*Corresponding author: Diyi Chen

Mailing Address: Institute of Water Resources and Hydropower Research, Northwest A\&F University, Shaanxi Yangling 712100, China

Telephone: 086-181-6198-0277

E-mail: diyichen@,nwsuaf.edu.cn

Abstract This paper addresses the stability of a hydro-turbine governing system under hydraulic excitations. During the operation of a hydro-turbine, water hammer with different intensities occurs frequently, resulting in the stochastic change of the cross-sectional area $(A)$ of the penstock. In this study, we first introduce a stochastic variable $u$ to the cross-sectional area $(A)$ of the penstock related to the intensity of water hammer. Using the Chebyshev polynomial approximation, the stochastic hydro-turbine governing model is simplified to its equivalent deterministic model, by which the dynamic characteristics of the stochastic hydro-turbine governing system can be obtained from numerical experiments. From comparisons based on an operational hydropower station, we verify that the stochastic model is suitable for describing the dynamic behaviors of the hydro-turbine governing system in full-scale applications. We also analyze the change laws of the dynamic variables under increasing stochastic intensity. Moreover, the differential coefficient with different 
values is used to study the stability of the system, and stability of the hydro-turbine flow with the increasing load disturbance is also presented. Finally, all of the above numerical results supply some basis for modeling efficiently the operation of large hydropower stations.

Key words: sustainable water energy; stochastic stability; hydro-turbine governing system; shock load.

\section{Introduction}

By 2014, the total installed capacity of sustainable water energy in China, representing approximately $25 \%$ of the worldwide installed capacity, exceeded $3 \times 10^{8} \mathrm{~kW}$. Furthermore, the installed global hydropower capacity is expected to double in the next 30 years [1-3], bringing it to $2 \times 10^{9} \mathrm{~kW}$. Clearly, hydropower has a promising prospect. Several challenging problems, however, exist in the operation of large hydropower stations. These problems include the vibrations of hydro-turbine generator units, the occurrence of water hammer in the penstock, and the increasing randomness of electric loads due to diverse power generation sources [4-6]. These problems are inseparably linked with the regulation of hydro-turbine governing systems. In recent years, studies of the hydro-turbine governing system have been mainly divided into two categories. The first category focuses on operational conditions and the hydro-structure of hydropower stations [7-13]. The second category focuses on the mathematical models of hydropower stations to optimize dynamic behaviors in terms of hydro-turbine control [14-22]. Conversely, the effects of the water hammer on the penstock are rarely considered in the mathematical modeling of hydro-turbine governing systems.

Water hammer is a commonly recognized general problem in transmission penstocks, and occurs when there is an abrupt change of flow in the penstock. Some possible causes leading to water hammer include, among others, the startup (or shutdown) of hydro-turbine generator units, 
rapid change in transmission conditions, and opening and closure of valves [23-27]. Moreover, high-intensity water hammer can lead to significant damages and even disruption of the hydro-turbine governing system [28-31]. The propagation process of water hammer occurring in the penstock can be divided into four stages, i.e. the compression process, the recovery process, the expansion process, and another recovery process. During the propagation process, frequent flow changing in the penstock makes water hammer with different intensities arise continuously, which leads to the stochastic change of the cross-sectional area $A$ of the penstock.

In light of these considerations, four significant innovations are presented in this paper. First, for a large hydropower station, we propose a stochastic model of the hydro-turbine governing system. Moreover, as pioneering research, we reduce the stochastic model to its equivalent deterministic model by using the Chebyshev polynomial approximation. Second, from numerical experiments based on a large currently operating hydropower station, we verify that the stochastic model is suitable for describing the behaviors of the hydro-turbine governing system in the operational process. Third, the effect of the stochastic intensity $D$ on the stability of the above system is analyzed. Fourth, we present the laws of stable ranges of the hydro-turbine flow $q$, the guide vane opening $y$, and the head loss $h_{q}$ at the hydro-turbine entrance under different conditions.

The rest of this paper is organized as follows. Section 1 presents the modeling process of the hydro-turbine governing system. In Section 2, the stochastic model of the hydro-turbine governing system and its simplified deterministic model are proposed. Numerical experiments along with detailed analyses are presented in Section 3. Finally, Section 4 summarizes the results.

\section{Mathematical modeling of a hydro-turbine governing system}

From Newton's second law of motion, the dynamic mathematical equations of the penstock system are 


$$
\left\{\begin{array}{l}
h_{t}=h_{r}-h_{f} \\
h_{f}=f_{1} q^{2} \\
h_{q}=Z_{01} q \tanh \left(T_{01} s\right)
\end{array},\right.
$$

where $h_{r}$ is the relative value of the rated head, $h_{t}$ is the relative value of the hydro-turbine head, $h_{f}$ is the friction head loss in the penstock, $h_{q}$ is the head loss at the hydro-turbine entrance, and $f_{1}$ is the friction factor of the penstock. The head loss $h_{q}$, considering the elastic water hammer effect, can be written as $[4,19]$

$$
h_{q 1}(s)=Z_{01} \frac{\pi^{2} T_{01} s+T_{01}^{3} s^{3}}{\pi^{2}+4 T_{01}^{2} s^{2}} q_{1}(s) .
$$

Turning Eq. (2) into the state-space equations results in

$$
\left\{\begin{array}{l}
x_{1}=x_{2} \\
x_{2}=x_{3} \\
x_{3}=-\frac{\pi^{2}}{T_{01}^{2}} x_{2}+\frac{1}{Z_{01} T_{01}^{3}} h_{q 1}, \\
q=-3 \pi^{2} x_{2}+\frac{4}{Z_{01} T_{01}} h_{q 1}
\end{array}\right.
$$

where $T_{01}$ is the elastic time constant of the penstock system, $T_{01}=\frac{L}{v} ; L$ is the length of the penstock; $v$ is the speed of the surge pressure wave in the penstock; and $Z_{01}$ is the resistance value of the hydraulic surge in the penstock system, which can be expressed as

$$
Z_{01}=\frac{v Q_{r}}{A g H_{r}},
$$

where $Q_{r}$ is the rated flow, $H_{r}$ is the rated head, $g$ is the acceleration of gravity, $A$ is the cross-sectional area of the penstock, and $q$ is the relative value of the hydro-turbine flow.

For a synchronous generator system, a first-order mathematical model is used, which is

$$
\omega=\frac{1}{T_{a b}}\left(m_{t}-m_{g 0}-e_{n} \omega\right),
$$

where $\omega$ is the angular speed of the generator, $\omega_{0}$ is the rated angular speed of the generator, $e_{n}$ is the accommodation coefficient, $m_{g 0}$ is the load disturbance of the generator, and $m_{t}$ is the output torque of the hydro-turbine. The traditional mathematical equation of the output torque for a 
hydro-turbine, proposed by an IEEE Working Group in 1993, is often adopted in the mathematical modeling of a hydro-turbine governing system [28], which is

$$
P_{m-I E E E}=A_{t} h_{t}\left(q-q_{n l}\right)-D_{t} y \omega .
$$

Since the organization structures (the mounting height of the guide vane, the flow angle of the guide vane, etc.) for different types of hydro-turbines are very different, Eq. (6) is just a general equation that cannot reflect the fine characteristics of the output power for a specific hydro-turbine in a transient process. In this paper, the output torque derived using the internal characteristics method is described as [19]

$$
\left\{\begin{array}{l}
h_{t}(t)=\frac{\omega}{g}\left[\left(\frac{\cot \gamma}{2 \pi b_{0}}+r \frac{\cot \beta}{F}\right) q(t)-\omega r^{2}\right] \\
m_{t}(t)=\rho\left[\left(\frac{\cot \gamma}{2 \pi b_{0}}+r \frac{\cot \beta}{F}\right) q_{1}-\omega r^{2}\right]
\end{array},\right.
$$

where $\gamma$ is the flow angle of the guide vane, $\beta$ is the flow angle of the middle area of the runner, $b_{0}$ is the mounting height of the guide vane, $r$ is the radius of the middle area of the runner, and $F$ is the area of the exit of the runner.

The hydraulic servo model is

$$
T_{y} \frac{d y}{d t}+y-y_{0}=u,
$$

where $T_{y}$ is the major relay connecter response time of the hydraulic servo model; $y_{0}$ is the initial incremental deviation of the guide vane opening; and $u$ is the output signal of the hydraulic servo model, which is described by Eq. (9):

$$
u=k_{p}(r-\omega)+k_{i} \int(r-\omega) d t+k_{d}(r-\omega) .
$$

From Eqs. (1)-(9), the dynamic mathematical equations of the hydro-turbine governing system 


$$
\left\{\begin{array}{l}
x_{1}=x_{2} \\
x_{2}=x_{3} \\
x_{3}=-\frac{\pi^{2}}{T_{01}^{2}} x_{2}+\frac{1}{Z_{01} T_{01}^{3}}\left(h_{0}-f q^{2}-h_{t}\right) \\
q=-3 \pi^{2} x_{2}+\frac{4}{Z_{01} T_{01}}\left(h_{0}-f q^{2}-h_{t}\right) \\
\omega=\frac{1}{T_{a b}}\left(m_{t}-m_{g 0}-e_{n} \omega\right) \\
y=\frac{1}{T_{y}}\left(k_{p}(r-\omega)+k_{i} x_{4}-k_{d} \omega-y+y_{0}\right) \\
x_{4}=r-\omega
\end{array} .\right.
$$

113 Considering $c=\frac{4}{Z_{01} T_{01}}, a=-\frac{\pi^{2}}{T_{01}^{2}}$, and $b=\frac{1}{4 T_{01}^{2}} c$, Eq. (10) can be rewritten as

$$
\left\{\begin{array}{l}
x_{1}=x_{2} \\
x_{2}=x_{3} \\
x_{3}=a x_{2}+\frac{1}{4 T_{01}^{2}} c\left(h_{0}-f q^{2}-h_{t}\right) \\
q=-3 \pi^{2} x_{2}+c\left(h_{0}-f q^{2}-h_{t}\right) \\
\omega=\frac{1}{T_{a b}}\left(m_{t}-m_{g 0}-e_{n} \omega\right) \\
y=\frac{1}{T_{y}}\left(k_{p}(r-\omega)+k_{i} x_{4}-k_{d} \omega-y+y_{0}\right) \\
x_{4}=r-\omega
\end{array} .\right.
$$

\section{Mathematical modeling of the stochastic hydro-turbine governing system}

Water hammer, which is basically a pressure wave, occurs when there is an abrupt change of

flow in the penstock. Due to the effect of the viscoelastic characteristics of the penstock wall, the cross-sectional area of the penstock changes correspondingly during water hammer propagation. Figure 1 illustrates the change law for the four stages of the water hammer propagation process.

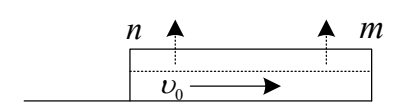

(a) the compression process

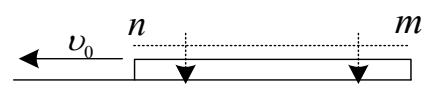

(c) the expansion process

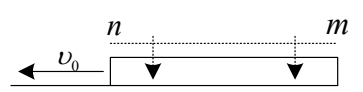

(b) the recovery process

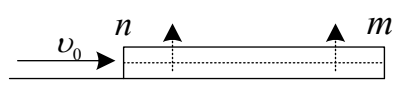

(d) the second recovery process

Fig. 1 Schematic description of the pressure wave propagation processes in the penstock. $(a)$ the 
compression process; $(b)$ the recovery process; $(c)$ the expansion process; $(d)$ the second recovery process.

Figure 1 shows the water in the penstock flowing from position $n$ to position $m$ with a steady flow $v_{0}$ during the stable operation of a hydropower station. As shown in Fig. 1(a), when the water gate at position $m$ is closed unexpectedly, water hammer arises immediately, and the water in the penstock starts flowing slowly down to position $m$ until the flow rate becomes zero. During this period, water in the penstock becomes compressed. The penstock wall, however, is in an expansive state. Since the pressure in the penstock is greater than the normal pressure during stable operation, the penstock wall comes into the recovery process as shown in Fig. 1(b). With regards to Fig. 1(b), the water flows from position $m$ to position $n$ with an increasing flow, and the penstock wall returns gradually to normal. Due to the non-zero velocity of the flow in the penstock, the water flow continues to decrease, which is shown in Fig. 1(c). At this moment, the penstock wall is in a compressive state because the pressure in the penstock is less than the normal pressure. When the flow rate decreases to zero, the penstock wall begins to enter into the second recovery process as shown in Fig. 1(d). Thereafter the penstock wall returns to normal.

The flow in the penstock changes continuously during operation of a hydropower station, especially in transient processes. Therefore, water hammer invariably arises during operation. Correspondingly, the cross-sectional area $A$ of the penstock changes with a degree of randomness, which has a close connection with the strength of the water hammer. From Eqs. (10) and (11), the variable $c$ can be rewritten as

$$
c=4 \frac{A g H_{r}}{T_{01} v Q_{r}} .
$$

Equation (12) can be used to show that the variable $c$ has the same randomness as the stochastic cross-sectional area $A$ of the penstock. Considering the change law of the stochastic cross-sectional 
area $A$ of the penstock in the aforementioned propagation processes, we innovatively introduce a stochastic parameter $u$ into the expression for the variable $c$, which satisfies the vaulted probability density function [32]. The probability density function of $u$ can be described as

$$
p(u)=\left\{\begin{array}{cc}
\frac{2}{\pi} \sqrt{1-u^{2}} ; & |u| \leq 1 . \\
0 ; & |u|>1 .
\end{array}\right.
$$

The $p(u)$ is illustrated in Fig. 2.

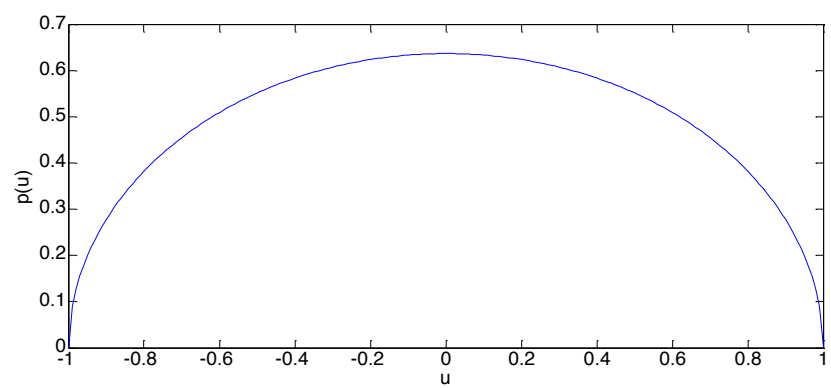

The stochastic variable $c$ can be expressed as

where $\bar{c}, D$, and $\frac{D}{2}$ are the mean value, stochastic intensity, and variance of the stochastic variable $c$, respectively. Based on $p(u)$, we used the Chebyshev polynomial approximation to transform the stochastic hydro-turbine governing system into the deterministic hydro-turbine governing system. The Chebyshev polynomial approximation is

$$
U_{n}(u)=\sum_{k=0}^{\frac{n}{2}} \frac{(-1)^{k}(n-k) !}{k !(n-2 k) !}(2 u)^{n-2 k}
$$

162 and its recurrence relation is

$$
u U_{n}(u)=\frac{1}{2}\left[U_{n-1}(u)+U_{n+1}(u)\right]
$$

164 In addition, the approximation property of the Chebyshev polynomial approximation can be

165 expressed as

$$
\int_{-1}^{1} \frac{2}{\pi} \sqrt{1-u^{2}} U_{i}(u) U_{j}(u) d u=\left\{\begin{array}{ll}
1, & i=j \\
0, & i \neq j
\end{array} .\right.
$$


167 From the approximation theory of orthogonal polynomials and the aforementioned analyses, the dynamic parameters in Eq. (11) can be written as

169

$$
\left\{\begin{array}{l}
x_{1}(t, u)=\sum_{i=0}^{N} x_{1(i)}(t) U_{i}(u) \\
x_{2}(t, u)=\sum_{i=0}^{N} x_{2(i)}(t) U_{i}(u) \\
x_{3}(t, u)=\sum_{i=0}^{N} x_{3(i)}(t) U_{i}(u) \\
q(t, u)=\sum_{i=0}^{N} q_{i}(t) U_{i}(u) \\
\delta(t, u)=\sum_{i=0}^{N} \delta_{i}(t) U_{i}(u) \\
\omega(t, u)=\sum_{i=0}^{N} \omega_{i}(t) U_{i}(u) \\
y(t, u)=\sum_{i=0}^{N} y_{i}(t) U_{i}(u) \\
x_{4}(t, u)=\sum_{i=0}^{N} x_{4(i)}(t) U_{i}(u)
\end{array}\right.
$$

where $N$ is the maximum number of Chebyshev polynomials.

Substituting Eq. (18) into Eq. (11), the stochastic hydro-turbine governing system can be rewritten as

$$
\left\{\begin{array}{l}
\frac{d}{d t}\left[\sum_{i=0}^{N} x_{1(i)}(t) U_{i}(u)\right]=\sum_{i=0}^{N} x_{2(i)}(t) U_{i}(u) \\
\frac{d}{d t}\left[\sum_{i=0}^{N} x_{2(i)}(t) U_{i}(u)\right]=\sum_{i=0}^{N} x_{3(i)}(t) U_{i}(u) \\
\frac{d}{d t}\left[\sum_{i=0}^{N} x_{3(i)}(t) U_{i}(u)\right]=a\left[\sum_{i=0}^{N} x_{2(i)}(t) U_{i}(u)\right]+\frac{1}{4 T_{01}^{2}} h_{v} \\
\frac{d}{d t}\left[\sum_{i=0}^{N} q_{i}(t) U_{i}(u)\right]=-3 \pi^{2}\left[\sum_{i=0}^{N} x_{2(i)}(t) U_{i}(u)\right]+h_{v} \\
\frac{d}{d t}\left[\sum_{i=0}^{N} \delta_{i}(t) U_{i}(u)\right]=\omega_{0}\left(\sum_{i=0}^{N} \omega_{i}(t) U_{i}(u)-r\right) \\
\frac{d}{d t}\left[\sum_{i=0}^{N} \omega_{i}(t) U_{i}(u)\right]=\frac{1}{T_{a b}}\left(\rho\left[\left(\frac{\cot \gamma}{2 \pi b_{0}}+r \frac{\cot \beta}{F}\right)\left[\sum_{i=0}^{N} q(t) U_{i}(u)\right]-\left[\sum_{i=0}^{N} \omega_{i}(t) U_{i}(u)\right] r^{2}\right]-m_{g 0}-e_{n}\left[\sum_{i=0}^{N} \omega_{i}(t) U_{i}(u)\right]\right) \\
\frac{d}{d t}\left[\sum_{i=0}^{N} y_{i}(t) U_{i}(u)\right]=\frac{1}{T_{y}}\left(k_{p}\left(r-\sum_{i=0}^{N} \omega_{i}(t) U_{i}(u)\right)+k_{i} x_{4}-k_{d} \frac{d}{d t}\left[\sum_{i=0}^{N} \omega_{i}(t) U_{i}(u)\right]-\sum_{i=0}^{N} y_{i}(t) U_{i}(u)+y_{s}\right) \\
\frac{d}{d t}\left[\sum_{i=0}^{N} x_{4(i)}(t) U_{i}(u)\right]=r-\sum_{i=0}^{N} \omega_{i}(t) U_{i}(u)
\end{array}\right.
$$

where $h_{v}=(\bar{c}+D u)\left(h_{0}-f_{1}\left[\sum_{i=0}^{N} q_{i}(t) U_{i}(u)\right]^{2}-\frac{y_{r}^{2}}{\left[\sum_{i=0}^{N} y_{i}(t) U_{i}(u)\right]^{2}}\left[\sum_{i=0}^{N} q_{i}(t) U_{i}(u)\right]^{2}\right)$. 
175 The nonlinear terms $\left[\sum_{i=0}^{N} q_{i}(t) U_{i}(u)\right]^{2}$ and $\left[\sum_{i=0}^{N} y_{i}(t) U_{i}(u)\right]^{2}$ in Eq. (19) can be expanded as 176

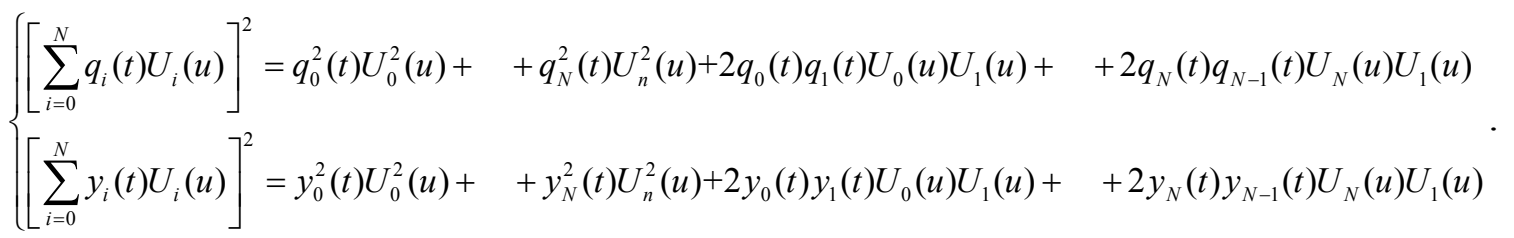

177 From Eq. (20), we can get the following equations

$$
\begin{aligned}
& U_{0}^{2}(u)=U_{0} \\
& 2 U_{0} U_{1}=2 U_{1} \\
& 2 U_{1} U_{2}=2\left(U_{3}+U_{1}\right)
\end{aligned}
$$

179 In light of this, Eq. (20) can be written in linear combinations. Assuming that the coefficients of $180 U_{i}(u)$ in the linear combinations are $C_{q i}$ and $C_{y i}$, respectively, Eq. (20) becomes

$$
\left\{\begin{array}{l}
{\left[\sum_{i=0}^{N} q_{i}(t) U_{i}(u)\right]^{2}=C_{0}(t) U_{0}(u)+\quad+C_{N}(t) U_{N}(u)=\sum_{i=0}^{N} C_{q i}(t) U_{i}(u)} \\
{\left[\sum_{i=0}^{N} y_{i}(t) U_{i}(u)\right]^{2}=C_{0}(t) U_{0}(u)+\quad+C_{N}(t) U_{N}(u)=\sum_{i=0}^{N} C_{y i}(t) U_{i}(u)}
\end{array}\right.
$$

182 and $D u\left[\sum_{i=0}^{N} q_{i}(t) U_{i}(u)\right]^{2}$ and $D u\left[\sum_{i=0}^{N} y_{i}(t) U_{i}(u)\right]^{2}$ can be simplified as

$$
\left\{\begin{array}{l}
D u\left[\sum_{i=0}^{N} q_{i}(t) U_{i}(u)\right]^{2}=D\left[u \sum_{i=0}^{N} C_{q(i)}(t) U_{i}(u)\right]=\frac{1}{2} D \sum_{i=0}^{N} C_{q(i)}(t)\left[U_{i-1}(u)+U_{i+1}(u)\right]=\frac{1}{2} D \sum_{i=0}^{N}\left[C_{q(i-1)}(t)+C_{q(i+1)}(t)\right] U_{i}(u), \\
D u\left[\sum_{i=0}^{N} y_{i}(t) U_{i}(u)\right]^{2}=D\left[u \sum_{i=0}^{N} C_{y(i)}(t) U_{i}(u)\right]=\frac{1}{2} D \sum_{i=0}^{N} C_{y(i)}(t)\left[U_{i-1}(u)+U_{i+1}(u)\right]=\frac{1}{2} D \sum_{i=0}^{N}\left[C_{y(i-1)}(t)+C_{y(i+1)}(t)\right] U_{i}(u)
\end{array}\right.
$$

184 where $C_{q(-1)}=0, C_{y(-1)}=0, C_{q(N+1)}=0$, and $C_{y(N+1)}=0$.

185 From the aforementioned analyses, the stochastic hydro-turbine governing system can be written as 


$$
\left\{\begin{array}{l}
\frac{d}{d t}\left[\sum_{i=0}^{N} x_{1(i)}(t) U_{i}(u)\right]=\sum_{i=0}^{N} x_{2 i}(t) U_{i}(u) \\
\frac{d}{d t}\left[\sum_{i=0}^{N} x_{2(i)}(t) U_{i}(u)\right]=\sum_{i=0}^{N} x_{3 i}(t) U_{i}(u) \\
\frac{d}{d t}\left[\sum_{i=0}^{N} x_{3(i)}(t) U_{i}(u)\right]=a\left[\sum_{i=0}^{N} x_{2 i}(t) U_{i}(u)\right]+\frac{\bar{c}}{4 T_{01}^{2}} k_{1}+\frac{D}{4 T_{01}^{2}} k_{2} \\
\frac{d}{d t}\left[\sum_{i=0}^{N} q(t) U_{i}(u)\right]=-3 \pi^{2}\left[\sum_{i=0}^{N} x_{2 i}(t) U_{i}(u)\right]+\bar{c} k_{1}+D k_{2} \\
\frac{d}{d t}\left[\sum_{i=0}^{N} \delta_{i}(t) U_{i}(u)\right]=\omega_{0}\left(\sum_{i=0}^{N} \omega_{i}(t) U_{i}(u)-r\right) \\
\frac{d}{d t}\left[\sum_{i=0}^{N} \omega_{i}(t) U_{i}(u)\right]=\frac{1}{T_{a b}}\left\{\rho\left[\left(\frac{\cot \gamma}{2 \pi b_{0}}+r \frac{\cot \beta}{F}\right)\left[\sum_{i=0}^{N} q(t) U_{i}(u)\right]-\left[\sum_{i=0}^{N} \omega_{i}(t) U_{i}(u)\right] r^{2}\right]-m_{g s}-e_{n}\left[\sum_{i=0}^{N} \omega_{i}(t) U_{i}(u)\right]\right\} \\
\frac{d}{d t}\left[\sum_{i=0}^{N} y_{i}(t) U_{i}(u)\right]=\frac{1}{T_{y}}\left(k_{p}\left(r-\sum_{i=0}^{N} \omega_{i}(t) U_{i}(u)\right)+k_{i} x_{4(i)}-k_{d} \frac{d}{d t}\left[\sum_{i=0}^{N} \omega_{i}(t) U_{i}(u)\right]-\sum_{i=0}^{N} y_{i}(t) U_{i}(u)+y_{s}\right) \\
\frac{d}{d t}\left[\sum_{i=0}^{N} x_{4(i)}(t) U_{i}(u)\right]=r-\sum_{i=0}^{N} \omega_{i}(t) U_{i}(u)
\end{array}\right.
$$

where $\quad k_{2}=u h_{0}-\frac{f_{1}}{2} \sum_{i=0}^{N}\left[C_{y(i-1)}(t)+C_{y(i+1)}(t)\right] U_{i}(u)-\frac{y_{r}^{2}}{2 \sum_{i=0}^{N} C_{y(i)}(t) U_{i}(u)}\left(\sum_{i=0}^{N}\left[C_{q(i-1)}(t)+C_{q(i+1)}(t)\right] U_{i}(u)\right), \quad$ and

$$
k_{1}=h_{s}-f_{1}\left(\sum_{i=0}^{N} C_{q(i)}(t) U_{i}(u)\right)-\frac{y_{r}^{2}}{\sum_{i=0}^{N} C_{y(i)}(t) U_{i}(u)}\left(\sum_{i=0}^{N} C_{q(i)}(t) U_{i}(u)\right)
$$

189 If the value of variable $N$ is assumed to be $\infty$, Eq. (24) is identical to Eq. (11). However, if the

190 variable $N$ has a finite value, Eq. (24) is an approximate expression of Eq. (11). Multiplying $U_{i}(u)$

191 and taking the mathematical expectation with regard to the stochastic variable $u$ on both sides of Eq.

192 (24), and setting $i=0,1,2,3$ and 4, we obtain 


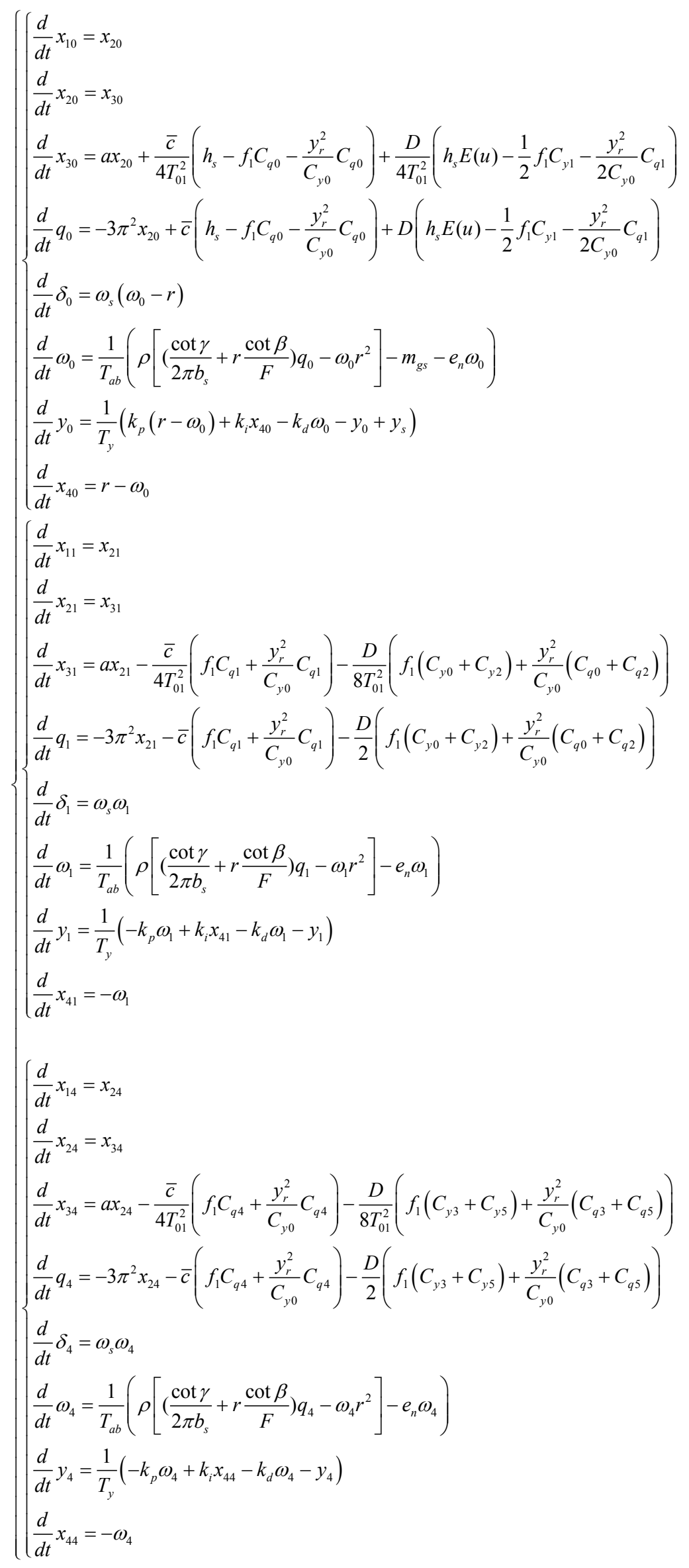

193 


$$
\left\{\begin{array}{l}
x_{1}(t, u)=\sum_{i=0}^{4} x_{1(i)}(t) U_{i}(u) \\
x_{2}(t, u)=\sum_{i=0}^{4} x_{2(i)}(t) U_{i}(u) \\
x_{3}(t, u)=\sum_{i=0}^{4} x_{3(i)}(t) U_{i}(u) \\
q(t, u)=\sum_{i=0}^{4} q_{i}(t) U_{i}(u) \\
\delta(t, u)=\sum_{i=0}^{4} \delta_{i}(t) U_{i}(u) \\
\omega(t, u)=\sum_{i=0}^{4} \omega_{i}(t) U_{i}(u) \\
y(t, u)=\sum_{i=0}^{4} y_{i}(t) U_{i}(u) \\
x_{4}(t, u)=\sum_{i=0}^{4} x_{4(i)}(t) U_{i}(u)
\end{array}\right.
$$

197 and their average responses are

198

$$
\left\{\begin{array}{l}
E\left[x_{1}(t, u)\right]=\sum_{i=0}^{4} x_{1(i)}(t) E\left[U_{i}(u)\right]=x_{10}(t) \\
E\left[x_{2}(t, u)\right]=\sum_{i=0}^{4} x_{2(i)}(t) E\left[U_{i}(u)\right]=x_{20}(t) \\
E\left[x_{3}(t, u)\right]=\sum_{i=0}^{4} x_{3(i)}(t) E\left[U_{i}(u)\right]=x_{30}(t, u) \\
E[q(t, u)]=\sum_{i=0}^{4} q_{i}(t) E\left[U_{i}(u)\right]=q_{0}(t, u) \\
E[\delta(t, u)]=\sum_{i=0}^{4} \delta_{i}(t) E\left[U_{i}(u)\right]=\delta_{0}(t) \\
E[\omega(t, u)]=\sum_{i=0}^{4} \omega_{i}(t) E\left[U_{i}(u)\right]=\omega_{0}(t) \\
E[y(t, u)]=\sum_{i=0}^{4} y_{i}(t) E\left[U_{i}(u)\right]=y_{0}(t) \\
E\left[x_{4}(t, u)\right]=\sum_{i=0}^{4} x_{4(i)}(t) E\left[U_{i}(u)\right]=x_{40}(t)
\end{array} .\right.
$$

\section{Stability of the stochastic hydro-turbine governing system}

The data for parameters of the stochastic hydro-turbine governing system in this paper are extracted from an existent currently operating large hydropower station, for which specific parameters are listed in Table 1. The layout of the center of the measured hydropower station is presented in Fig. 3. The plan of the data of the measured hydro-turbine flow is shown in Fig. 4. 
Table 1 Main parameters of the existing hydropower station

\begin{tabular}{|c|c|c|c|c|}
\hline Component & Parameter & Symbol & Value & Unit \\
\hline Penstock & \multicolumn{4}{|c|}{ Material: Steel } \\
\hline \multirow{6}{*}{ Hydro-turbine } & Length & $\bar{L}$ & 216 & $\mathrm{~m}$ \\
\hline & Diameter & $D_{L}$ & 5 & $\mathrm{~m}$ \\
\hline & \multicolumn{4}{|c|}{ Type: HLD294-LJ-178 } \\
\hline & Maximum head & $H_{\max }$ & 113.5 & $\mathrm{~m}$ \\
\hline & Rated head & $H_{\text {rated }}$ & 103 & $\mathrm{~m}$ \\
\hline & Rated power & $P_{\text {rated }}$ & 29000 & $\mathrm{Kw}$ \\
\hline \multirow{10}{*}{ Generator } & Rated speed & $n_{\text {rated }}$ & 428.6 & $\mathrm{r} / \mathrm{min}$ \\
\hline & Rated flow & $Q_{\text {rated }}$ & 32.86 & $\mathrm{~m}^{3} / \mathrm{s}$ \\
\hline & Zero load flow & $Q_{n l}$ & 4.5 & $\mathrm{~m}^{3} / \mathrm{s}$ \\
\hline & Guide vane opening & $Y_{\max }$ & 205 & $\mathrm{~mm}$ \\
\hline & Zero load guide vane opening & $Y_{n l}$ & $21 \%$ & -- \\
\hline & \multicolumn{4}{|c|}{ Type: FS29-14/4000 } \\
\hline & Active power & $P_{\text {e-rated }}$ & 29 & MW \\
\hline & Direct axis synchronous reactance & $X_{d}$ & 0.9736 & $\Omega$ \\
\hline & Direct axis transient reactance & $X_{d}$ & 0.2836 & $\Omega$ \\
\hline & $\begin{array}{l}\text { Quadrature synchronous axis } \\
\text { reactance }\end{array}$ & $X_{q}$ & 0.6169 & $\Omega$ \\
\hline \multirow{9}{*}{ Governor } & Quadrature transient axis reactance & $X_{q}$ & 0.6169 & $\Omega$ \\
\hline & Rated terminal voltage & $U_{S \text {-rated }}$ & 6.3 & $\mathrm{kV}$ \\
\hline & Damping factor & $D_{t}$ & 5 & -- \\
\hline & Transient time constant of axis & $T_{d 0}$ & 5.4 & S \\
\hline & \multicolumn{4}{|c|}{ Type: CVT-80-4 (PID) } \\
\hline & Permanent speed droop & $b_{p}$ & $0 \sim 10 \%$ & -- \\
\hline & proportional gain & $k_{p}$ & $0.5 \sim 20$ & s \\
\hline & integral gain & $k_{i}$ & $0.05 \sim 10$ & $\mathrm{~s}$ \\
\hline & differential gain & $k_{d}$ & $0 \sim 5$ & S \\
\hline
\end{tabular}

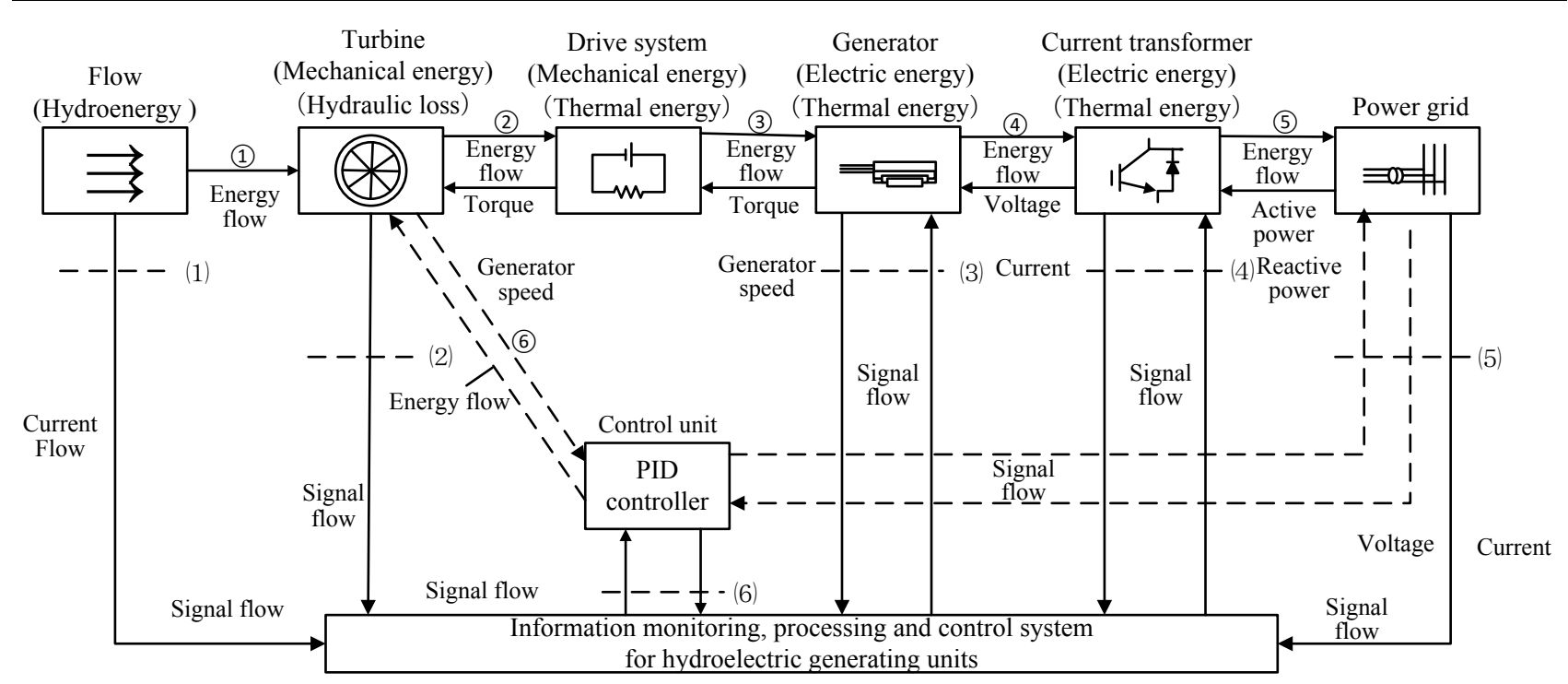

Fig. 3 Layout of the center of the measured hydropower station. Circled numbers refer to interfaces 
for energy transfer. Numbers in brackets refer to interfaces for information transfer.

From Fig. 3, the relationship of the material flow, energy flow and information flow in the

hydropower station can be seen clearly. Specifically referring to Fig. 3, the energy interface (1) can

210 be considered as the hydro-energy carried by flowing water. With hydraulic loss and mechanical loss,

211 the hydro-turbine converts hydro-energy into mechanical energy. At the energy interfaces (2) and

212 (3), mechanical energy is exchanged between the hydro-turbine and generator. The mechanical

213 energy of the generator is converted into electrical energy by the electromagnetic coupling effect at

214 the energy interface (4). In the process of energy transfer from the interface (4) to (5), the electrical

215 energy is transferred to the power gird through the transformer. In light of the aforementioned

216 analyses, the process of the interface (1) to (5) is the main path of the energy flow for the

217 hydro-turbine governing system. In addition, there is another energy flow which is used to control

218 the guide vane opening, namely that at (6). This energy is regularly supplied by the auxiliary power

219 system.

rotation speeds and the hydraulic forces for the turbine runner are measured at information interface

(2). The collected information at interface (4) includes the torque, voltage, power and temperature

for the generator. The information transferred at interface (5) includes the voltage of power grid, the active power, the reactive power, and other items. The information at interface (6) contains the guide vane opening and the turbine speed. To verify the validity of the stochastic model, here, the measurement system of the information interface (1) in Fig. 3 is presented in Fig. 4.

Referring to Fig. 4, the hydro-turbine flow is measured by sensors located on the inside wall of the penstock. The information about the turbine flow is transmitted by the communication cable at $220 \mathrm{~V}$ to the control box installed in the hydro-turbine floor, and then the control box passes the 
information to the hydraulic measurement system of type GER9000.

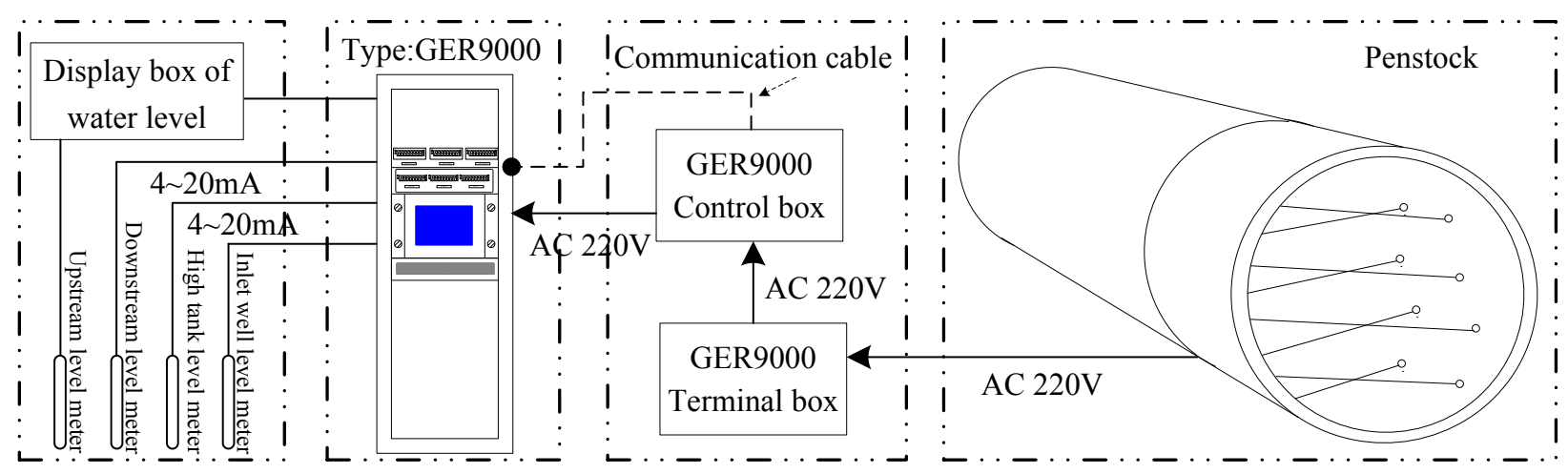

Fig. 4 The plan of the measurement system of the hydro-turbine flow. equations of the model, it has provided a serious of parameters, and some of the parameters do not affected by the location, running time and generation hours of hydropower stations. Hence, the simulation process is adjusted by sensitivity analysis, and the final values of these parameters are determined when the model output data coincide with the measured data.

(1) Definition of the velocity of water hammer. From Ref. [33], the velocity of water hammer in

(2) Definition of the Coefficient of Head loss in penstock. From the construction data of Nazixia

(3) Definition of the sectional area for penstock. According to the construction data of Nazixia 
as $5 \mathrm{~m}$ without counting the effect of temperature, and the sectional area is calculated as 19.625

$\mathrm{m}$.

(4) Definition of the PID parameters. The Nazixia hydropower station adopts the PID governor

Table 2 The sensitivity results of the parameters for the hydropower station.

\begin{tabular}{ccccccccccccc}
\hline Parameter & $L$ & $\alpha$ & $f$ & $r$ & $k_{p}$ & $k_{i}$ & $k_{d}$ & $T_{a b}$ & $e_{n}$ & $h_{s}$ & $y_{r}$ & $T_{y}$ \\
\hline $\mathrm{Sp}$ & 0 & 0 & 0 & 0.141 & 0 & 0 & 0 & 0 & 0.002 & 0 & 0 & 0 \\
\hline
\end{tabular}

4.1.3 Parameter calibration

From Tab. 2, it is known that the reference input $r$ and the regulation factor $e_{n}$ are the sensitive parameters that affect the turbine flow. Using the data of the turbine flow monitoring in the rated condition, the following relationship can be obtained.

$$
\left\{\begin{array}{l}
e_{n}=1 \\
r=0.1072
\end{array}\right.
$$

\subsubsection{Model verification}


269 of simulated errors is $0.62 \%$, the minimum value of simulated errors is $0.605 \%$. The comparison 270 between the simulated flow and measured flow is shown in Fig. 5.

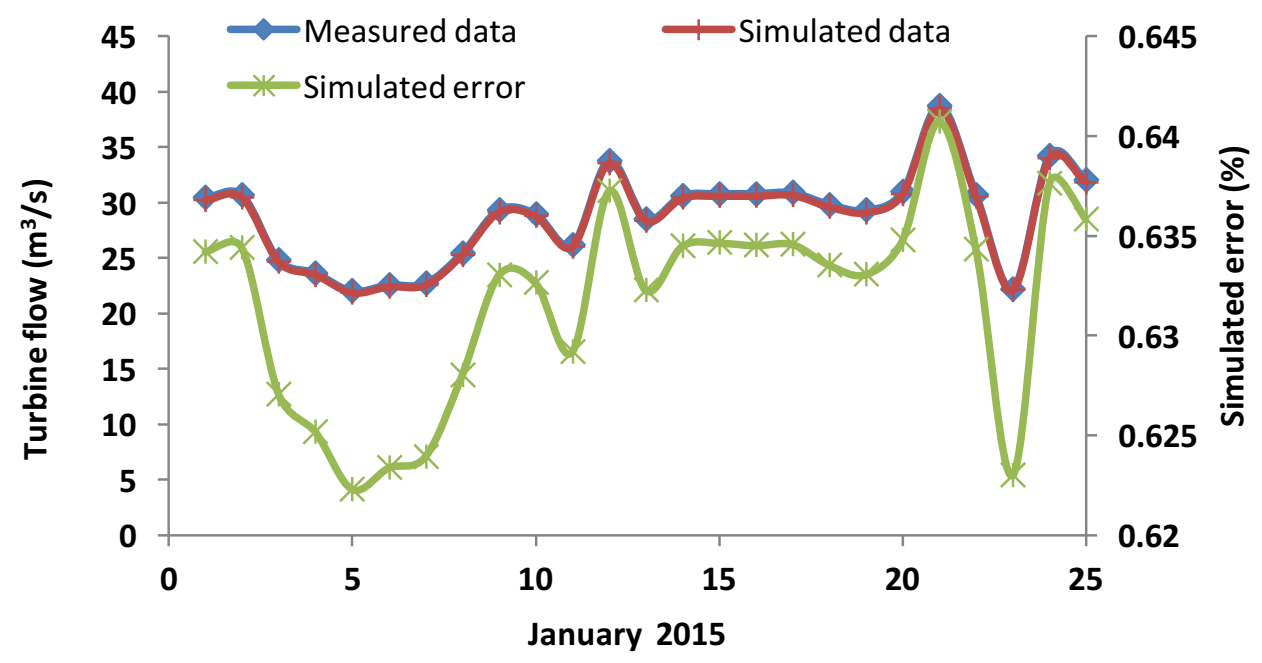

(a) Comparison of measured flow and simulated flow in January 2015.

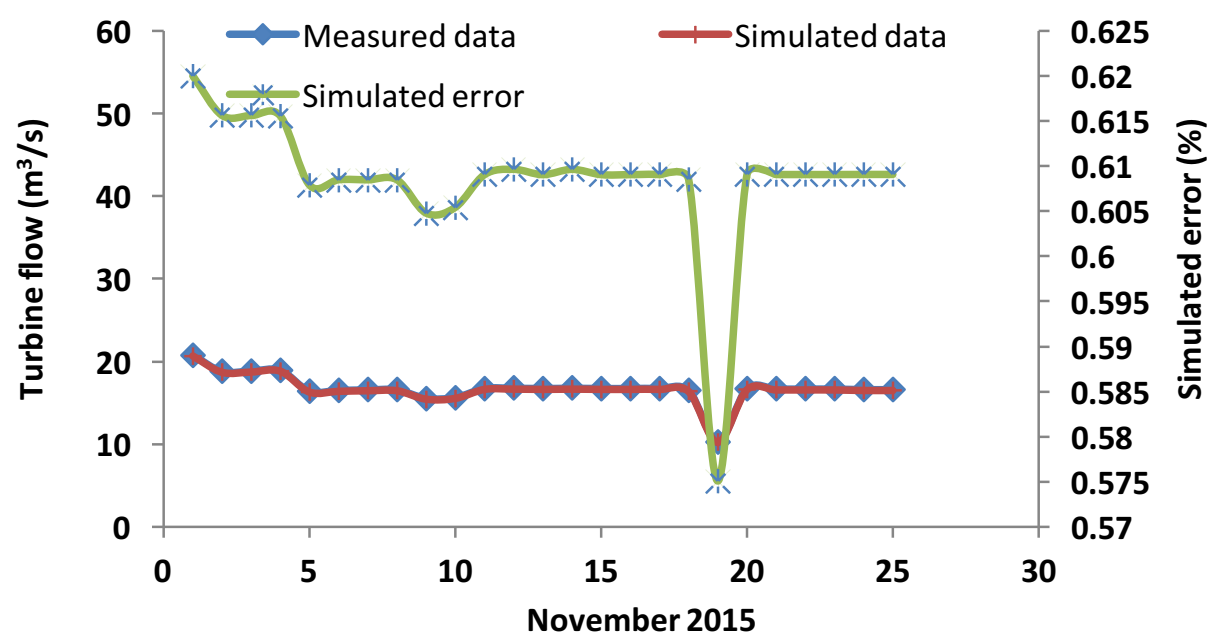

(b) Comparison of measured flow and simulated flow in November 2015.

Fig. 5 Comparison between the simulated flow and measured flow of January 2015 and November

To verify the stochastic model is better than the traditional model, the turbine flow calculated from the stochastic model with $\mathrm{D}=0.2$ is simulated, and the comparison of the simulated errors from the stochastic model and the deterministic model (Eq. 11) are presented in Fig. 6. From Fig. 6, the simulated error of the stochastic model with the intensity $\mathrm{D}=0.2$ is decreased by almost $50 \%$. Therefore, the model considering the stochastic shape change of the penstock wall is more accurate 
281 than the deterministic model.

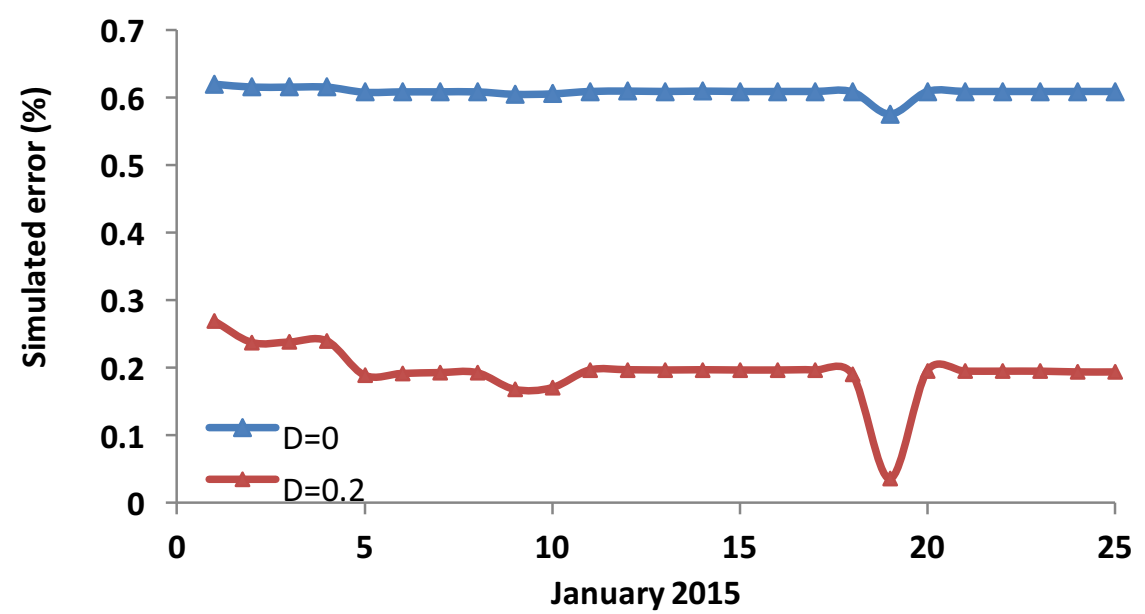

(a) Comparison of simulated errors in January 2015

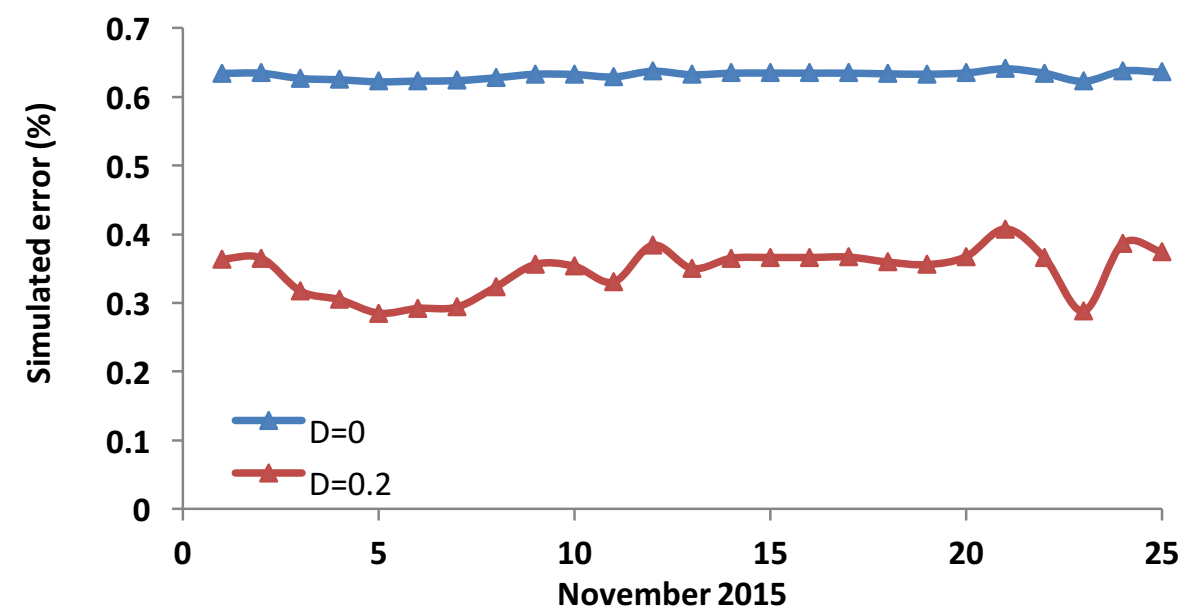

(b) Comparison of simulated errors in November 2015

Fig. 6 Comparison of the simulated errors from the stochastic model and the deterministic model

Three different cases can be identified for analysis. First, considering that a variety of reasons during operation of a hydro-turbine can lead to water hammer with different intensities (such as

290 disturbance of the electrical load, opening or closure of a valve, loose connections of pipe, and 291 intrusion of dirty water into the water distribution system), in Case 1 we analyze the change laws of 292 the dynamic variables with the increasing stochastic intensity $D$. Second, from the control point of view, the differential coefficient $k_{\mathrm{d}}$ reflects and predicts the change trends of deviation signals; that is 
294 to say, a correction signal is introduced to the PID controller to obtain an advanced control effect 295 before the deviation signals of the hydro-turbine governing system increase. Thus, in Case 2, 296 different values of the differential coefficient $k_{\mathrm{d}}$ are simulated to study the dynamic behaviors of the 297 system. Third, random load disturbance is considered to be a threat to any hydropower station in 298 terms of economy, stability, and safety. Therefore, Case 3 focuses on the responses of the system to 299 increasing load disturbance $m_{\mathrm{g} 0}$.

300 Case 1 The hydro-turbine governing system operates with the rated load. The load disturbance 301 is not considered, i.e. $m_{\mathrm{g} 0}=0$. The values of the PID controller parameters $k_{\mathrm{p}}, k_{\mathrm{i}}$, and $k_{\mathrm{d}}$ are 1,3 and 3024 , respectively.

303 The dynamic evolutions of the hydro-turbine $q$, the generator speed $\omega$, the head loss $h_{\mathrm{q}}$ at the 304 hydro-turbine entrance and the guide vane opening $y$ with respect to the stochastic intensity $D$ are 305 presented in Fig. 6.

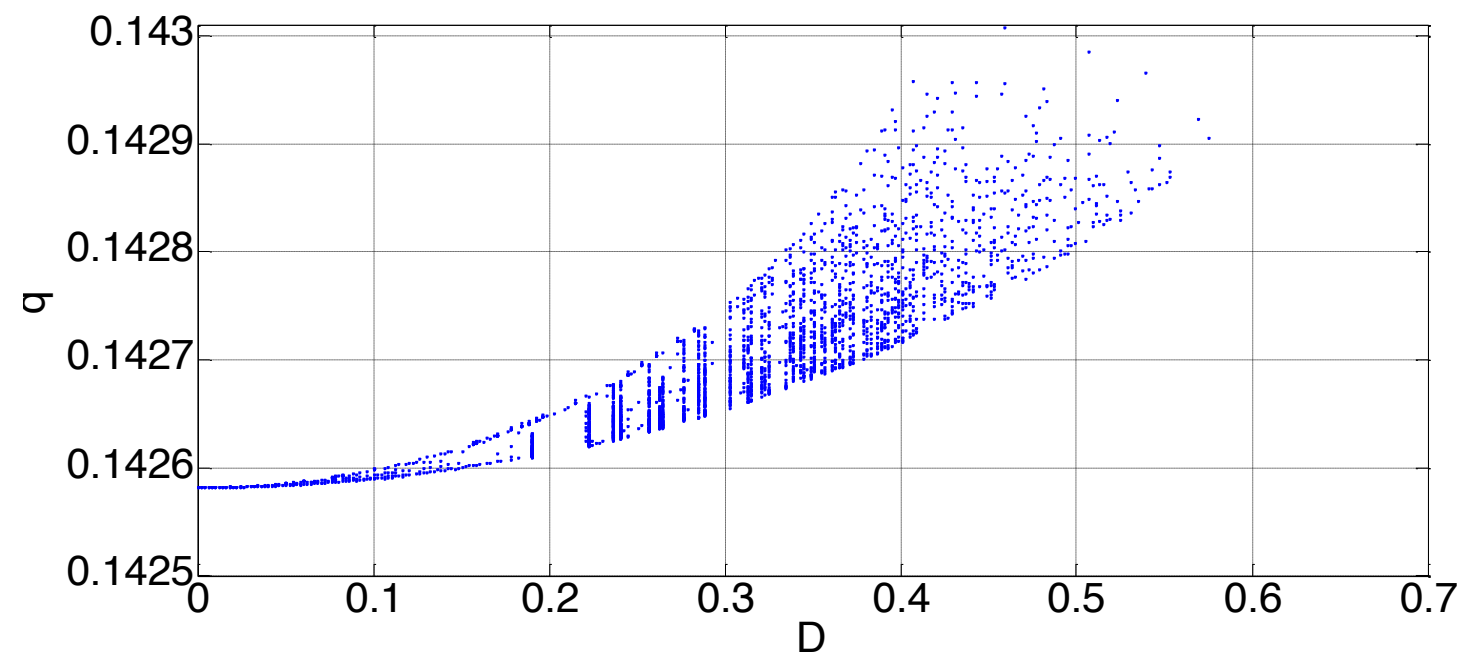


308

309

310

311

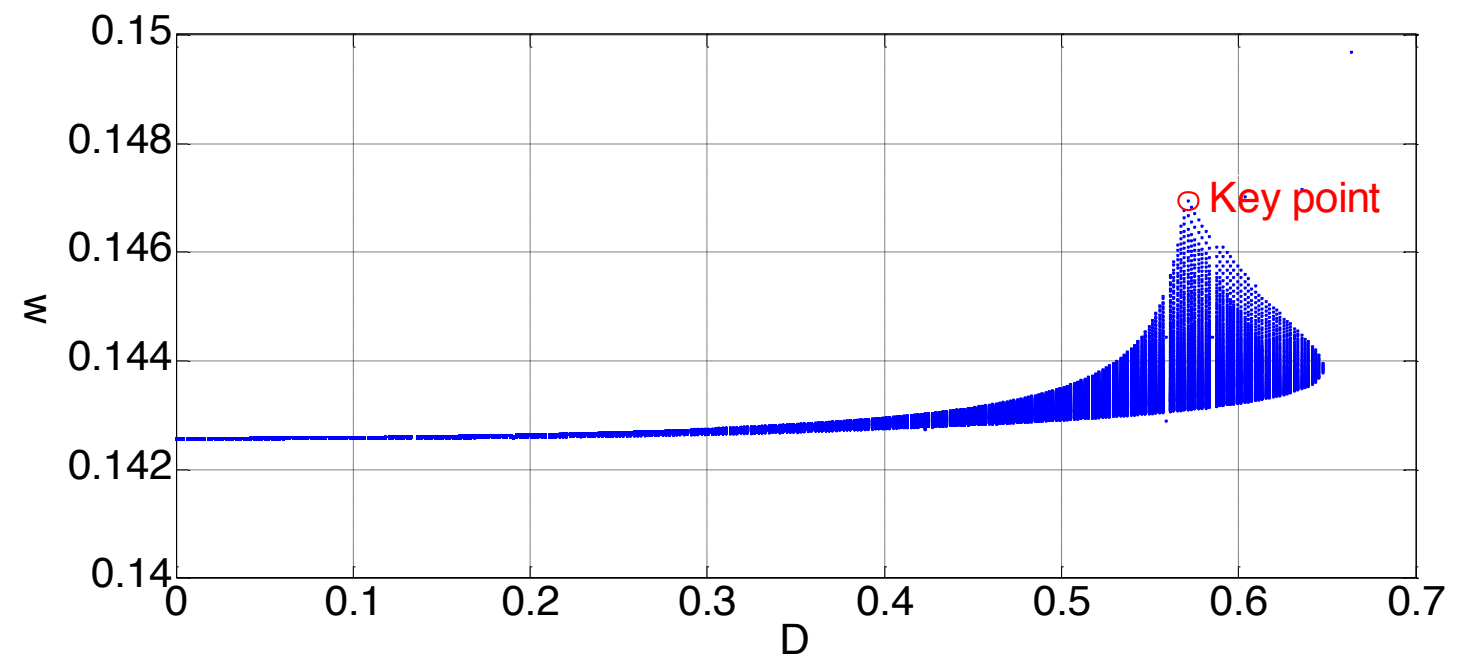

(b) Dynamic evolution of $\omega$

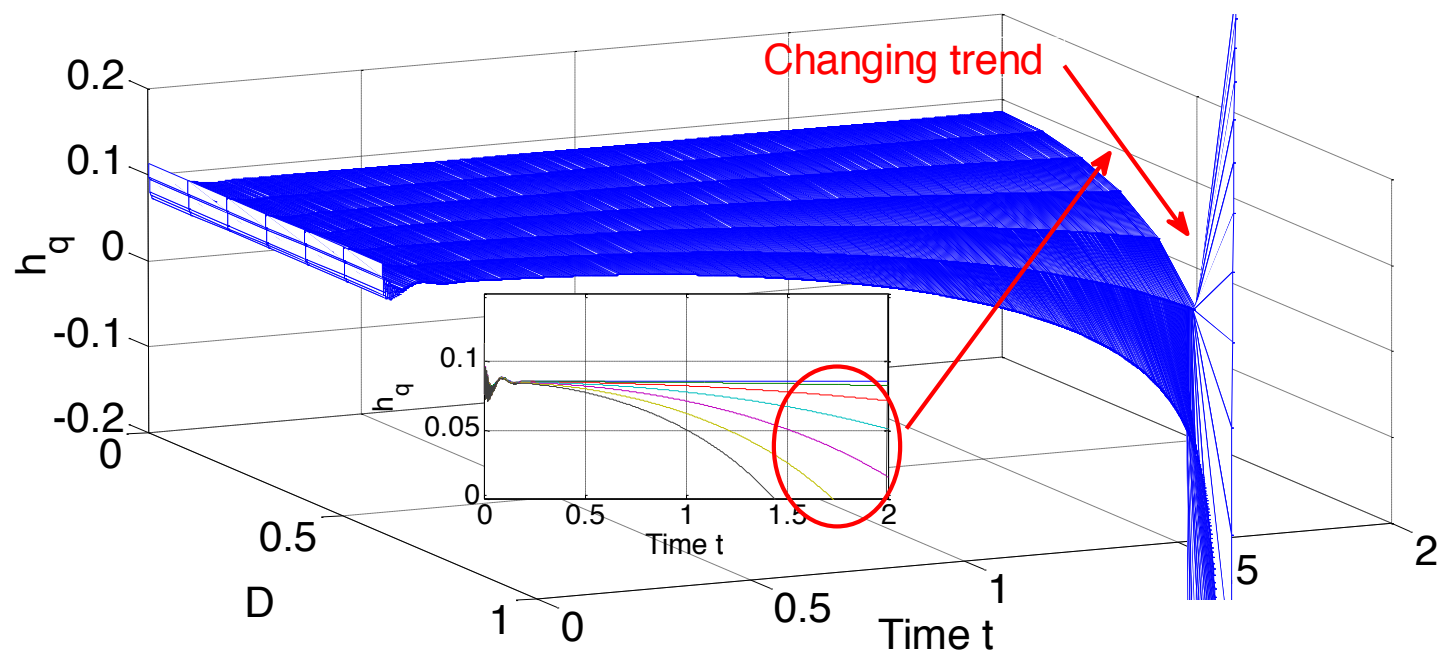

(c) Dynamic evolution of $h_{\mathrm{q}}$

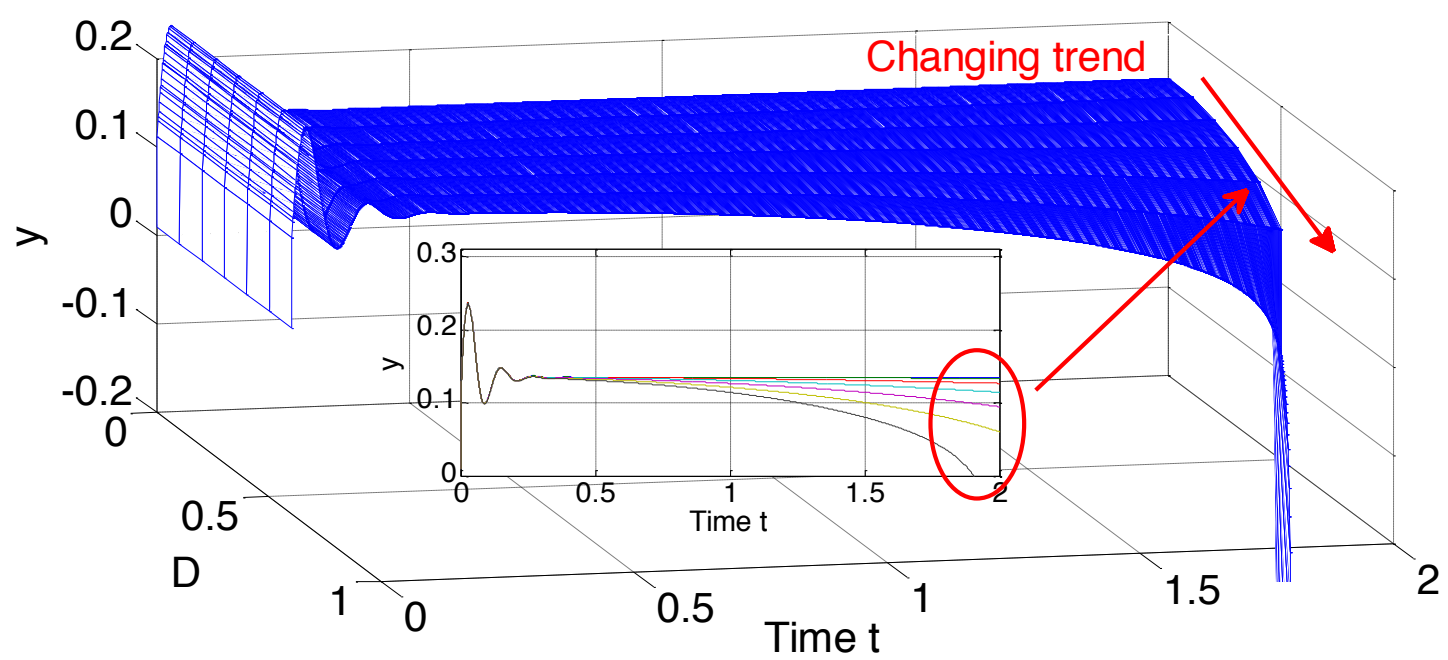

(d) Dynamic evolution of $y$ 
314 Fig. 6 The numerical applications regarding the relative deviations of the hydro-turbine flow $q$, the head $\operatorname{loss} h_{\mathrm{q}}$ at the hydro-turbine entrance, and the guide vane opening $y$ with respect to the stochastic intensity D. (a) Dynamic evolution of $q$; (b) Dynamic evolution of $\omega$; (c) Dynamic evolution of $h_{q} ;(d)$ Dynamic evolution of $y$;

Figure 6 illustrates that as $0<D<0.1$, the dynamic characteristics flow $q$, generator speed $\omega$, head loss $h_{\mathrm{q}}$ and the guide vane opening $y$ show very slight changes, which do not threaten the stable operation of the hydro-turbine governing system, and in this stage the PID controller is effective. When $0.1<D<0.6$, the hydro-turbine flow $q$ exhibits chaotic behavior. Note, the response of $q$ to different values for $D$ increases slightly, which indicates that its relative deviation shows only slight variations (changing from 0.1426 to 0.1430 ). When $D=0.57$, there exists a critical value for the generator speed $\omega$. When $D>0.6$, the hydro-turbine governing system is severely affected by water hammer and becomes completely out of control. Interestingly, the generator entering into a runaway state lags behind the hydro-turbine. In the whole stage the head loss $h_{\mathrm{q}}$ at the hydro-turbine entrance and the guide vane opening $y$ decreases gradually with the increasing time $t$.

Case 2 The hydro-turbine governing system operates with the rated load. The load disturbance is not considered, i.e. $m_{\mathrm{g} 0}=0$. The values of the PID controller parameters $k_{\mathrm{p}}$ and $k_{\mathrm{i}}$ are 1 and 3 , respectively. The differential coefficient $k_{\mathrm{d}}$ changes from 0 to 50 .

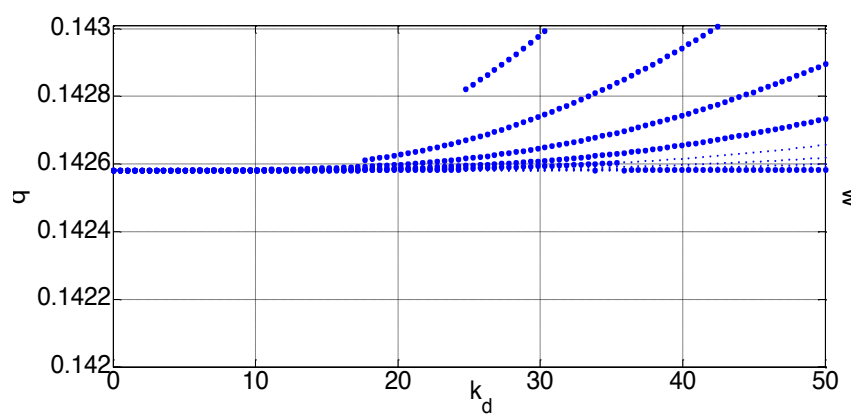

(a) Stable range of $q$ with $D=0$

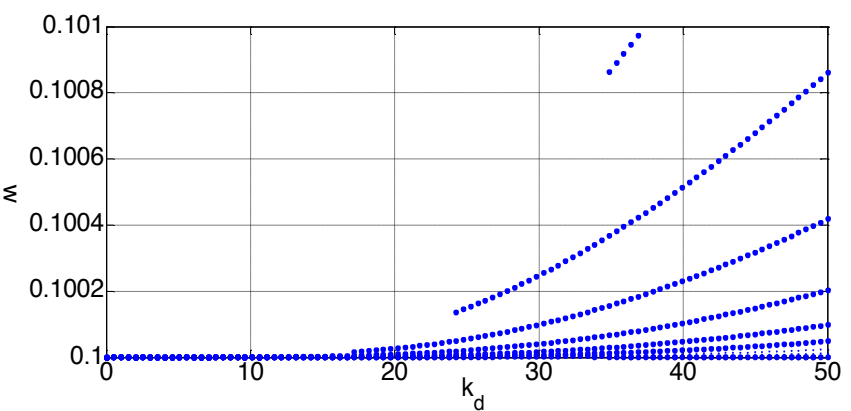

(b) Stable range of $\omega$ with $D=0$ 

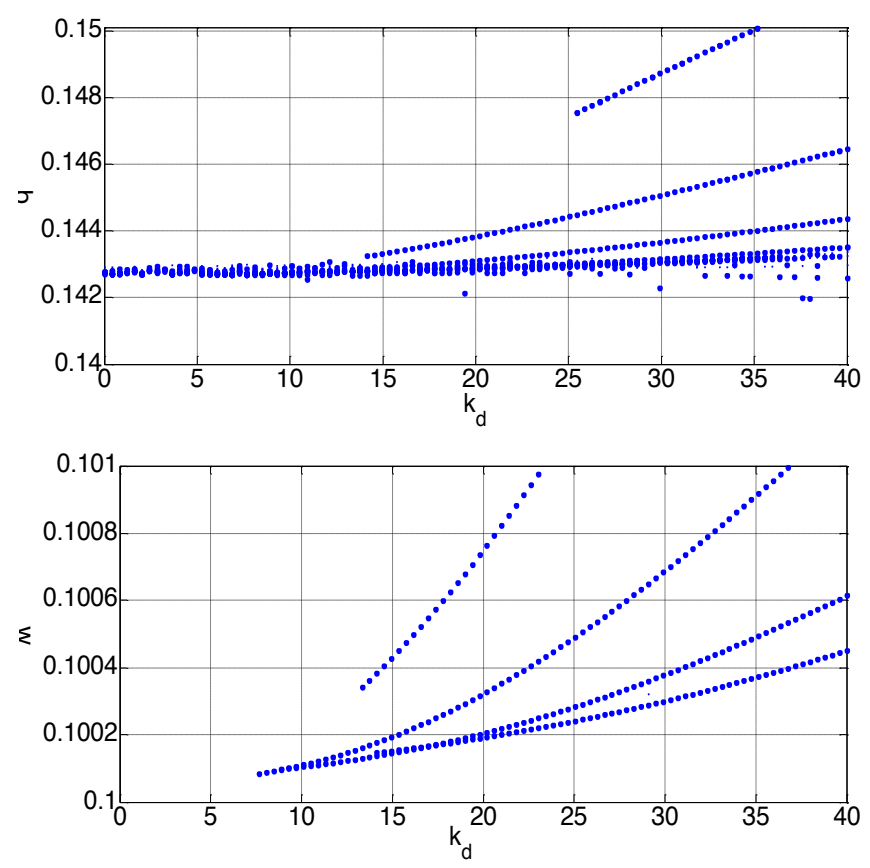

(d) Stable range of $\omega$ with $D=0.4$

Fig. 7 Stable range of the relative deviations of the hydro-turbine flow $q$ and the angular speed $\omega$ of the generator with respect to the increasing differential coefficient $k_{\mathrm{d}}$ and the stochastic intensity $D$ with 0 and 0.4. (a) Stable range of $q$ with $D=0 ;(b)$ Stable range of $\omega$ with $D=0$; (c) Stable range of $q$ with $D=0.4 ;(d)$ Stable range of $\omega$ with $D=0.4$.

As highlighted in Fig. 7, the dynamic behaviors of the hydro-turbine governing system with $D=$ 0 and $D=0.4$ show large differences. Specifically, the responses of the hydro-turbine flow $q$ and the angular speed $\omega$ of the generator show that their relative deviations remain unchanged until they reach certain values of the differential coefficient $k_{\mathrm{d}}$, and the respective $k_{\mathrm{d}}$ values at $D=0$ and $D=$ 0.4 are very different. These responses indicate that the stochastic intensity $D$ is related to the stable range of the system. Moreover, the $k_{\mathrm{d}}$ values at $D=0.4$ are less than those with $D=0$, which needs to be addressed in actual operations, especially in transient processes.

Case 3 The hydro-turbine governing system operates with the rated load. The values of the PID controller parameters $k_{\mathrm{p}}, k_{\mathrm{i}}$ and $k_{\mathrm{d}}$ are 1,3 , and 4, respectively. The stochastic intensity $D$ is 0.2 , and the load disturbance $m_{\mathrm{g} 0}$ changes from 0 to 2 . 


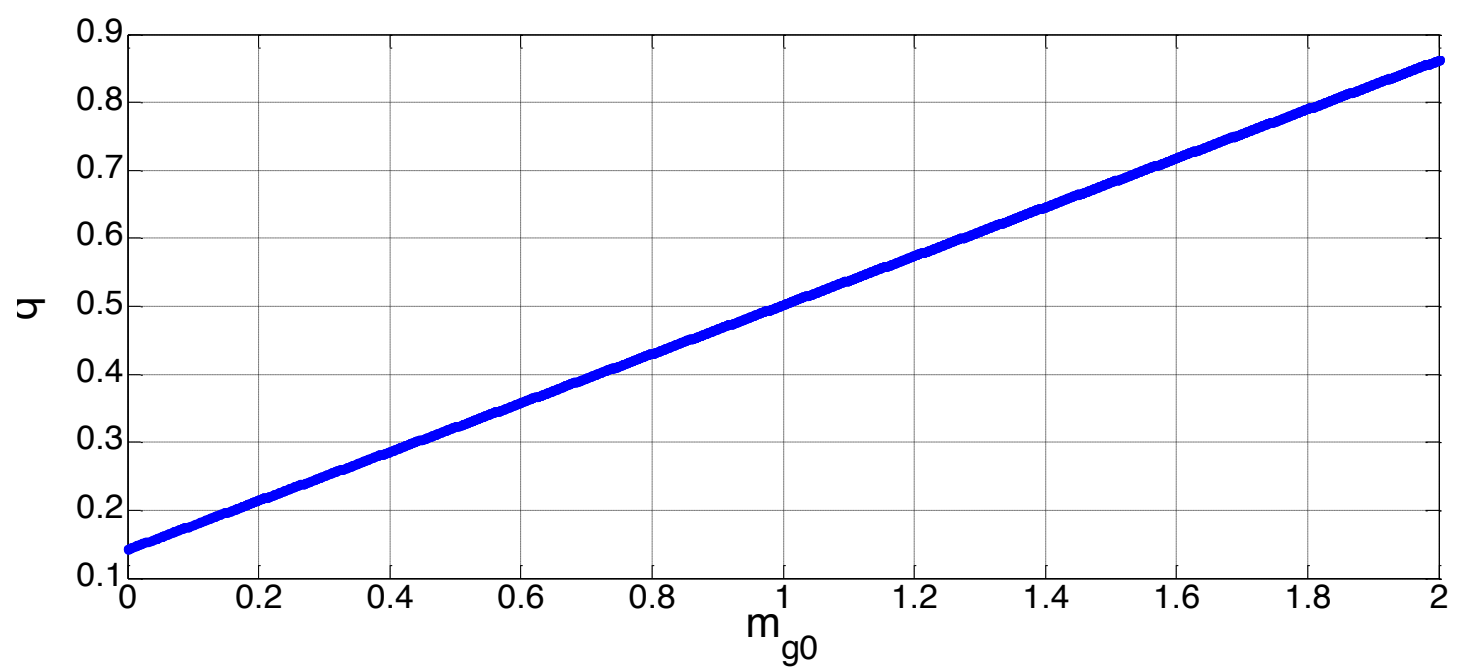

Fig. 8 Stable range of the relative deviation of the hydro-turbine flow $q$ with respect to the increasing load disturbance $m_{\mathrm{g} 0}$.

The hydro-turbine governing system operates with the rated load excited by the positive load disturbance. Theoretically speaking, to meet the demand of the electrical load and preserve the stable operation of the system, the hydro-turbine flow $q$ should increase. From the numerical experiment illustrated in Fig. 9, the stable value of the hydro-turbine flow $q$ is shown to increase at a constant rate when the load disturbance $m_{\mathrm{g} 0}$ changes from 0 to 2 . Note that the relative deviation of the hydro-turbine flow $q$ is proportional to the increased load disturbance $m_{\mathrm{g} 0}$.

\section{Conclusions}

361 hydro-turbine governing system, and we reduced the stochastic hydro-turbine governing system to a 362 deterministic system. Then assuming that a hydro-turbine governing system operates with the rated 363 load, the deterministic hydro-turbine governing system was investigated to determine the effect of 364 the stochastic intensity $D$ on the hydro-turbine governing system, the dynamic behaviors at 365 increasing values of the differential coefficient $k_{\mathrm{d}}$, and the change law of the hydro-turbine flow $q$ in response to difference values of load disturbance. The stochastic stability of the system is 
367 investigated with the continuous change of the stochastic intensity (D). It should be noted that this 368 paper only focuses on the stability of the system with the changing value of PID parameters. This is 369 because the change of the PID parameter to avoid the instability problem caused by stochastic 370 disturbance is easier and costs less, compared with changing basic structural parameters. The 371 analysis justifies the following recommendations regarding the operation of large hydropower 372 stations, especially for facilities with long penstocks: (a) the guide vane opening $y$ should be 373 changed slowly, and (b) the differential coefficient $k_{\mathrm{d}}$ should take a small value.

\section{Acknowledgements}

This work was supported by the Scientific Research Foundation of the National Natural Science Foundation Outstanding Youth Foundation (51622906), National Science Foundation (51479173), Fundamental Research Funds for the Central Universities (201304030577), scientific research funds of Northwest A\&F University (2013BSJJ095), the Scientific Research Foundation on Water Engineering of Shaanxi Province (2013slkj-12), the Science Fund for Excellent Young Scholars from Northwest A\&F University and the Shaanxi Nova program (2016KJXX-55).

\section{References}

382 [1] Ren JZ, Gao SZ., Tan SY, Dong LC, Scipioni A. Role prioritization of hydrogen production 383 technologies for promoting hydrogen economy in the current state of China. Renew. Sust. Energ. 384 Rev. 2015; 41: 1217-1229.

385 [2] Huang HL, Yan Z. Present situation and future prospect of hydropower in China. Renew. Sust. 386 Energ. Rev. 2009; 13: 1652-1656.

387 [3] Garcia AJ, Uemori MKI, Echeverria JJR, Bortoni ED. Design Requirements of Generators 388 Applied to Low-Head Hydro Power Plants. IEEE T. Energ. Conv. 2015; 30: 1630-1638.

[4] Zeng Y, Zhang LX, Guo YK. The generalized Hamiltonian model for the shafting transient 
analysis of the hydro turbine generating sets. Nonlinear Dyn. 2014; 76: 1921-1933.

[5] Trivedi C, Gandhi BK, Cervantes MJ, Dahlhaug OG. Experimental investigations of a model Francis turbine during shutdown at synchronous speed. Renew. Energ. 2015; 83: 828-836.

[6] Bergant A, Simpson AR, Tijsseling AS. Water hammer with column separation: a history review. J. Fluid Structures. 2006; 22: 135-37.

[7] Jian YA, Ming H, Jin S. Stochastic analysis of water hammer considering unsteady friction. International Conference on Sustainable Power Generation and Supply 2009; 1-4: 1983-1986.

[8] Zhang QF, Karney B, Suo LS, Colombo AF. Stochastic analysis of water hammer and applications in reliability-based structural design for hydro turbine penstocks. J. Hydraul.

[9] Sarasua JI, Perez-Diaz JI, Wihelmi JR, Sanchez-Fernandez JA. Dynamic response and governor tuning of a long penstock pumped-storage hydropower plant equipped with a pump-turbine and a

[10] Yang WJ, Yang JD, Guo WC, Norrlund P. Response time for primary frequency control of hydroelectric generating unit. Int. J. Elec. Power 2016; 74: 16-24.

405 [11] Ramos TP, Marcato ALM, Brandi RBD, Dias BH, da Silva IC. Comparison between piecewise 406 linear and non-linear approximations applied to the disaggregation of hydraulic generation in 407 long-term operation planning. Int. J. Elec. Power 2015; 71: 364-372.

408 [12] Liu Y, Liu N, Xie C. Analysis of transient electric field distribution inside the large generator 409 under strong surge voltage. Int. J. Elec. Power 2014; 60: 121-125.

410 [13] Perez-Diaz JI, Sarasua JI, Wilhelmi JR. Contribution of a hydraulic short-circuit 411 pumped-storage power plant to the load-frequency regulation of an isolated power system. Int. J. 412 Elec. Power 2014; 62: 199-211. 
413 [14] Oliveira EJ, Honorio LM, Anzai AH, Oliveira LW, Costa EB. Optimal transient droop 414 compensator and PID tuning for load frequency control in hydropower system. Int. J. Elec. Power $415 \quad 2015 ; 68: 345-355$.

416 [15] Guo WC, Yang JD, Wang MJ, Lai X. Nonlinear modeling and stability analysis of 417 hydro-turbine governing system with sloping ceiling tailrace tunnel under load disturbance. Energ. 418 Convers. Manage. 2015; 106: 127-138.

419 [16] Zeng Y, Zhang LX, Guo YK, Dong KH. Hydraulic decoupling and nonlinear hydro turbine 420 model with sharing common conduit. Proceeding of the CSEE. 2012; 32: 103-108. (in Chinese)

421 [17] Liu XL, Liu C. Eigenanalysis of oscillatory instability of a hydropower plant including water 422 conduit dynamics. IEEE T. Power Syst. 2007; 22: 675-681.

423 [18] Shen ZY. Regulating of hydro-turbine. China WaterPower Press, 2010. [In Chinese]

424 [19] Perez-Diaz JI, Sarasua JI, Wilhelmi JR. Contribution of a hydraulic short-circuit 425 pumped-storage power plant to the load-frequency regulation of an isolated power system. Int. J. 426 Elec. Power 2014; 199-211.

427 [20] Guo WC, Yang JD, Yang WJ, Chen JP, Teng Y. Regulation quality for frequency response of 428 turbine regulating system of isolated hydroelectric power plant with surge tank. Int. J. Elec. Power, $429 \quad 2015 ; 73: 528-538$.

430 [21] Guo WC, Yang JD, Chen JP, Yang WJ, Teng Y, Zeng W. Time response of the frequency of 431 hydroelectric generator unit with surge tank under isolated operation based on turbine regulating 432 modes. Electr. Pow. Compo. Sys., 2015; 43(20):2341-2355.

433 [22] Guo WC, Yang JD, Chen JP, Wang MJ. Nonlinear modeling and dynamic control of 434 hydro-turbine governing system with upstream surge tank and sloping ceiling tailrace tunnel. 435 Nonlinear Dynam., 2016; 84(3):1383-1397.

436 [23] Klemen N, Igor S. Modelling and internal fuzzy model power control of a francis water turbine. 437 Energies. 2014; 7: 874-16. 

hydroelectric power plant. Eng. Fail. Anal. 2016; 68: 87-100. [25] Azizipanah-Abarghooee R, Golestaneh F, Gooi HB, et al. Corrective economic dispatch and operational cycles for probabilistic unit commitment with demand response and high wind power. $442 \quad$ Appl. Energ. 2016; 182: 634-651.

[26] Terzija V, Preston G, Stanojevic V. Synchronized measurements-based algorithm for short 444 transmission line fault analysis. IEEE T. Smart. Grid 2015; 6(6): 2639-2648.

445 [27] Teran LA, Aponte RD, Munoz-Cubillos J, et al. Analysis of economic impact from erosive wear 446 by hard particles in a run-of-the-river. Energy 2016; 113: 1188-1201.

447 [28] IEEE Working Group. Hydraulic-turbine and turbine control-models for system dynamic 448 studies. IEEE T. Power Syst. 1992; 7: 167-33.

449 [29] Perez-Blanco H, Richards S, Leyde B. When intermittent power production serves transient $450 \quad$ loads. Appl. Therm. Eng. 2013; 50(2): 1549-1556.

451 [30] Beevers D, Branchini L, Orlandini V, De Pascale A, Perez-Blanco H. Pumped hydro storage 452 plants with improved operational flexibility using constant speed Francis runners. Appl. Energ. $453 \quad 2015 ; 137: 629-637$.

454 [31] Kwan ES, Heilman CB, Shucart WA, Klucznik RP. Enlargement of basilar artery aneurysms 455 following balloon occlusion-“water-hammer effect” Report of two cases. J Neurosurg. 1991; 75: $456 \quad 963-8$.

457 [32] Xu, W. Numerical analysis methods for stochastic dynamical system, 2013. [In Chinese] 458 [33] Zhao, X, Zhang XY, Zhao MD, Tong HY. Hydraulics, China Electric Power Press, 2009. [In 459 Chinese] 